\title{
What are the Most Responsible Pathogenic Bacteria in the Adenoid for Intractable Acute Otitis Media in Japanese Children?
}

\author{
Masashi Hamada ${ }^{*}, 1,3$, Miyako Sekiguchi ${ }^{1}$, Kazuhiro Yamakawa $^{2}$ and Kahori Hirose ${ }^{3}$ \\ ${ }^{I}$ Department of Otolaryngology Tokai University School of Medicine, Japan \\ ${ }^{2}$ Department of Otolaryngology Fukui Red Cross Hospital, Japan \\ ${ }^{3}$ Department of Otolaryngology, Kochi Medical School, Japan
}

\begin{abstract}
Introduction: Although Streptococcus pneumoniae (SP), Haemophilus influenzae (HI), and Moraxella catarrhalis $(M C)$ are major pathogenic bacteria of acute otitis media (AOM) in children, responsibility of their resistance to antimicrobial agents for intractable AOM has not been cleared. In this study, cultured bacteria from the adenoid of otitis-prone children were compared with those of children who had no apparent episodes of AOM to know the most responsible pathogens for intractable AOM.
\end{abstract}

Methods: Sixty-eight children who had episodes of recurrent or persistent AOM were subjected to this study and 19 children without apparent episodes of AOM but with obstructive sleep apnea were taken as controls. Nasopharyngeal swab specimens were obtained from the adenoid transorally during the adenoidectomy, instead of conventional transnasal harvesting, to avoid contamination. Prevalence of $S P, H I$, and $M C$ in each group was compared using the chi-squared or Fischer's exact test, and $p$-values $<0.05$ were considered significant.

Results: $S P$ was identified in $60.3 \%$ of otitis-prone children and in $52.6 \%$ of control children, and this difference indicated no statistically significance $(p=0.54)$. HI was isolated from $77.9 \%$ of subjects and from $47.4 \%$ of controls, and the difference revealed significant $(p=0.009)$. Above all, beta-lactamase negative $H I(B L N A R)$ was caught in $39.7 \%$ of the study group, but in none of the control group $(p=0.002)$. $M C$ was identified in $32.4 \%$ and in $5.3 \%$, individually, with significant difference $(p=0.04)$.

Conclusion: $H I$ was more frequently isolated from otitis-prone children, and was considered to make AOM more intractable. The pathogenic role of $M C$ for AOM may be evident.

Keywords: Otitis-prone children, adenoidectomy, nasopharyngeal culture, Streptococcus pneumoniae, Haemophilus influenzae, Moraxella catarrhalis.

\section{INTRODUCTION}

Acute otitis media (AOM) is the most common disease in children over the world, especially in infants and toddlers. Streptococcus pneumoniae (SP), non-typeable Haemophilus influenzae (HI), and Moraxella catarrhalis $(M C)$ are well known to be major bacteria which cause AOM. $S P$ has long been the leading pathogen of AOM [1-3], but $H I$ was recently reported to increase its frequency $[3,4]$. In addition, pathogenesis of $M C$ has not yet been sufficiently elucidated [5]. Furthermore, bacterial resistance to antimicrobial agents has become an increasing problem in the treatment of AOM, and thereby has induced $\mathrm{AOM}$ to be more intractable in many countries [6-10].

On the other hand, adenoidectomy is generally accepted to be an effective treatment for otitis media with effusion (OME) persisted in rather older children [11, 12]. It nowadays becomes more difficult to distinguish persistent otitis media in infants and toddlers from classical OME,

*Address correspondence to this author at the Department of Otolaryngology, Tokai University, School of Medicine, 143 Shimokasuya, Isehara, 259-1193, Japan; Tel: +81-463-93-1121; Fax: +81-463-94-1611;

E-mails:mhamada@is.icc.u-tokai.ac.jp,mhenttusm@yahoo.co.jp since resistant bacteria has been proved in the middle ear effusion [13, 14]. In addition, adenoid has been recently closed up as a reservoir of antibiotics-resistant bacteria [13, 14]. However, the role of adenoid and bacteria on site for intractable AOM is still unclear.

In this paper, we aimed to clarify what are the most responsible bacteria in the adenoid of otitis-prone (OP) Japanese children for intractability of AOM in the present time and to discuss about the role of adenoid as a reservoir of those bacteria. To achieve this purpose, nasopharyngeal swab specimens taken transorally from the inside of adenoid of OP children were compared with those of children who had no apparent episodes of AOM.

\section{SUBJECTS AND METHODS}

Sixty-eight children (43 boys and 25 girls) who had episodes of recurrent AOM or persistent otitis media were subjected to this study. They underwent adenoidectomy and/or tympanostomy tube insertion under general anesthesia in Kochi Medical School hospital from 2002 through 2007. Recurrent AOM means 4 episodes of AOM or more during the last 6 months and persistent otitis media has fluid collection in the middle ear observed over 3 months. Nineteen children (10 boys and 9 girls) without apparent 
episodes of AOM but with obstructive sleep apnea (OSA), in whom adenotonsillectomy were indicated during the same period, were taken as controls. Age distribution was from 11 months to 3 years (mean 1.8 years) in the study (OP) group and from 1 to 3 years (mean 2.5 years) in the control (OSA) group. In the present study, we focused on the intractable AOM in infants and toddlers, and thereby limited the age distribution up to 3 years. Written informed consent was taken from guardians of all children. This study conformed to the principles outlined in the Declaration of Helsinki, and was approved by the ethical committee of Kochi Medical School.

The nasopharyngeal swab specimens were obtained transorally from the adenoid during the surgery, instead of conventional transnasal harvest, in order to eliminate the contamination (Fig. 1). Nasopharyngeal samples were inoculated on blood agar, chocolate agar, and other appropriate plates, if applicable. The plates were incubated for $24-48$ hours at $37^{\circ} \mathrm{C}$ with $5 \%$ carbon dioxide. Colonies were identified based on the generally accepted methods.

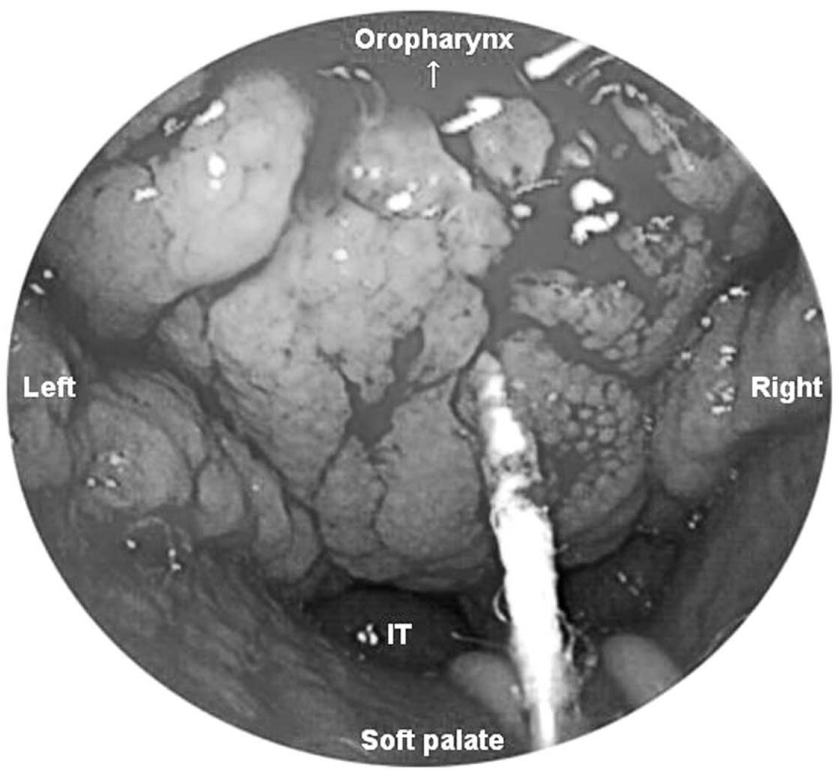

Fig. (1). Endoscopic view for transoral harvest of nasopharyngeal specimen by the use of swab. Soft palate was elevated by transnasal catheter and the swab was put deeply inside the adenoid without oral contamination. IT: inferior turbinate of left nose.

The minimum inhibitory concentrations (MICs) of the isolates to antibiotics were determined according to the standard methods of the Clinical Laboratory Standards Institute (CLSI). $S P$ with MICs $\leqq 0.06 \mathrm{ug} / \mathrm{ml}$ for penicillin G was defined as penicillin-susceptible SP (PSSP), that with MICs of $0.125-1.0 \mathrm{ug} / \mathrm{ml}$ as penicillin-intermediate susceptible $S P$ (PISP), and that with MICs $\geqq 2 \mathrm{ug} / \mathrm{ml}$ as penicillin-resistant $S P(P R S P)$. Beta-lactamase negative $H I$ with MICs $\geqq 1 \mathrm{ug} / \mathrm{ml}$ for ampicillin was defined as BLNAR.

Prevalence of $S P, H I$, and $M C$ in each group was compared using the Fischer's exact test and $p$-values $<0.05$ were considered significant.

\section{RESULTS}

Bacteria isolated from nasopharyngeal swab of the study OP group and the control OSA group were shown in
Figs. (2, 3), respectively. One hundred and fifty-seven isolates were obtained from 68 children with intractable AOM, whereas 44 were cultured from 19 children without AOM but with OSA. SP, $H I$, and $M C$ altogether accounted for more than $70 \%$ of all isolates in the OP group and for $45 \%$ in the OSA group.

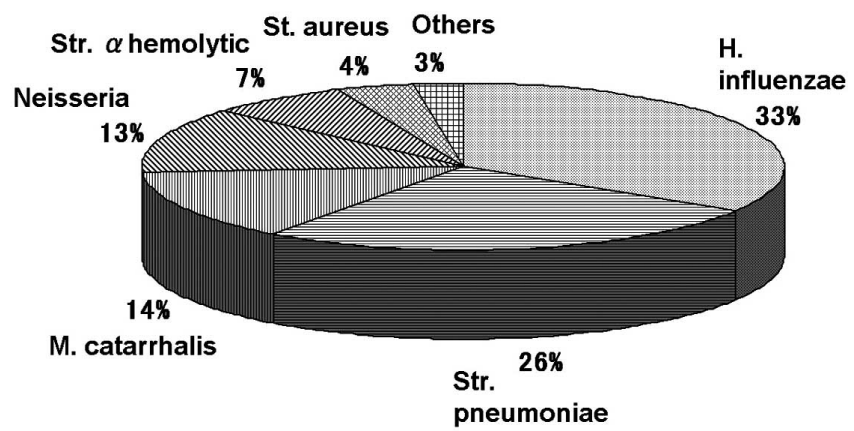

Fig. (2). Bacteria isolated from the adenoid of otitis-prone children. One hundred and fifty-seven isolates were cultured from 68 children, and 3 major pathogens (Streptococcus pneumoniae, Haemophilus influenzae, and Moraxella catarrhalis) together reached above $70 \%$ of all isolates.

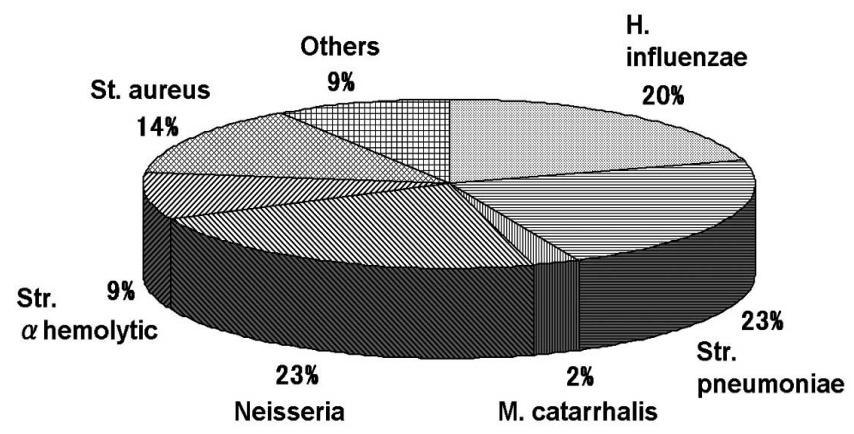

Fig. (3). Bacteria isolated from the adenoid of children with obstructive sleep apnea. Forty-four isolates were cultured from 19 children, and 3 major pathogens accounted for $45 \%$ of all isolates.

The prevalence of $S P, H I$, and $M C$ were presented in Fig. (4). $S P$ was identified in $60.3 \%$ of samples from OP children and in $52.6 \%$ from OSA children, and this indicated no statistically significant difference $(p=0.54)$. Regarding the antibiotics-resistance, PISP or PRSP was found in $52.9 \%$ of the OP group and $42.1 \%$ of the OSA group $(p=0.4)$. $H I$ was isolated from $77.9 \%$ of the study group and from $47.4 \%$ of the control group, and the difference between two groups revealed statistically significant $(p=0.009) . B L N A R$ was caught in $39.7 \%$ of the study group and in none of the control group. This difference was significant statistically $(p=0.002) . M C$, all of which had beta-lactamase, was identified in $32.4 \%$ and in $5.3 \%$, individually, with showing a significant difference $(p=0.04)$.

\section{DISCUSSION}

Bacteria cultured from middle ear fluid, regardless it seems purulent or not, are thought to be more specific pathogens to AOM. However, tympanocentesis for drainage and diagnosis is not always carried out in the clinic. In addition, the detection rate by the standard culture is not high enough to know the real pathogens of AOM even if middle ear fluids are harvested [15]. Polymerase chain reaction (PCR) may be more sensitive to prove the existence of 
bacteria $[16,17]$, but this technique has not yet been established as clinical use and still has a question if DNA of bacteria detected really means pathognomonic. On the other hand, nasopharyngeal culture by the use of transnasal swab is more acknowledged to represent the pathogenic bacteria of AOM than that from middle ears. This method is still a gold standard, but may have a chance of contamination and thereby can lead us to misunderstanding. That is a reason that we took the nasopharyngeal swab transorally without touching any place in the nose and mouth in order to know the true nasopharyngeal colonization and further real pathogens of intractable AOM.

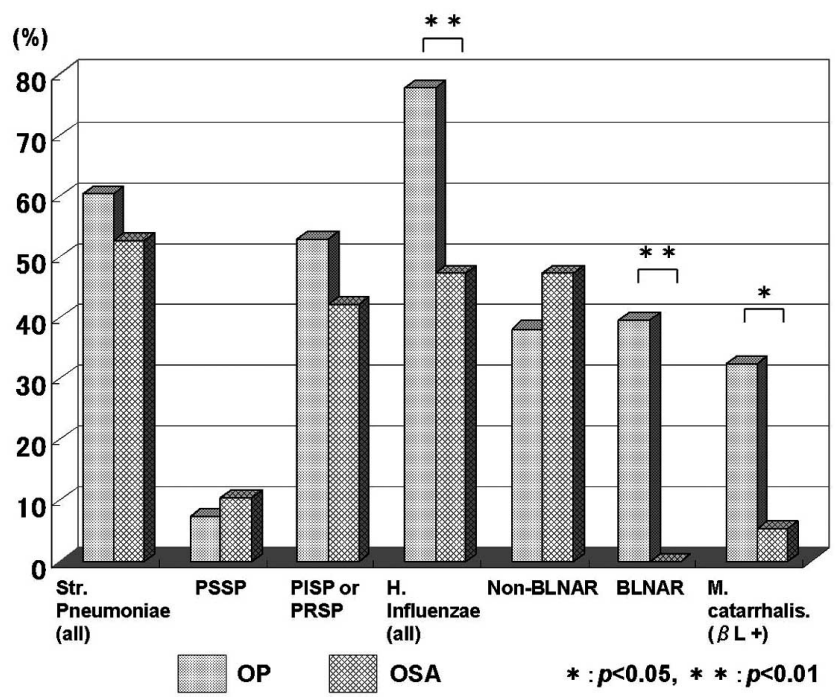

Fig. (4). Comparison of prevalence of 3 major pathogenic bacteria between otitis-prone (OP) group and obstructive sleep apnea (OSA) group. There was significant difference between two groups in the prevalence of total Haemophilus influenzae, BLNAR, and Moraxella catarhalis.

As a result, $S P, H I$, and $M C$ were still considered to be 3 major pathogens of $A O M$, because their total percentage to all isolates reached over $70 \%$ from the pure nasopharyngeal specimens of the OP children and this proportion was far higher compared to OSA group. Above all, $H I$ was the most frequently cultured in the OP group, and its prevalence was significantly higher than that of the control OSA children. These results may indicate that $H I$ resides in the adenoid tissue of the OP children and that $H I$ is the most convincing candidate to cause AOM intractable. Hotomi et al. [18] have recently suggested that $H I$ may act a role of intracellular pathogens to contribute to persistent existence and intractable course of otitis media. In addition, further more evident difference was obtained between OP group and OSA group in the positivity of BLNAR. HI likely survives even after an attempt of decolonization by repetitive administration of antibiotics [19]. BLNAR may be induced by such an inappropriate management of recurrent AOM, and thus never be isolated in OSA children who had no episodes of AOM in this study. Furthermore, the biofilm formation of $H I$ was clearly shown by Moriyama et al. [20] and this may result in persistent course of otitis media.

On the other hand, $H I$ was positively isolated as well in the control OSA children in the present study. $H I$ has been highly proved to be resident in the adenoid of the classical OME children either by PCR or by the standard culture [21].
Furthermore, Brook et al. [22] reported that $H I$ was isolated even from the healthy children and was thereby thought to play some role for adenoid growth. The relationship between $H I$ and adenoids remains so unclear that significance of the difference in the prevalence between the OP and OSA children shown in the present study should be further discussed.

Surprisingly, $S P$ is highly proved in the adenoid of the control children as well as of OP children. PISP and PRSP were majority of $S P$ in both groups, but there seems no difference in the prevalence of these resistant $S P$ between two groups. $S P$ is a component of normal flora in children and can be easily spread among children through daycare centers [23, 24]. PISP and PRSP are supposed to replace the susceptible organisms after initiation of antibiotics treatment [25]. In Japan, antibiotics has been likely used even for mild acute upper respiratory tract infections in the pediatric primary care, and this trend may be one of the reasons that the significant difference was not obtained in the resistant $S P$ prevalence between the OP group and the OSA group. Furthermore, since even PISP and PRSP are thought to be controlled by the high dose of amoxicillin administration [26] which is currently prevailed in Japan, $S P$ may exist in the adenoid neither with presenting with active AOM nor with being completely eradicated.

Although $M C$ has been generally accepted as one of 3 major bacteria responsible for AOM, its pathogenesis and virulence have been long on the argument [5]. Current researches have led to a better understanding of the molecular mechanisms involved in $M C$ pathogenesis [27]. Broides et al. [28] showed $M C$ was more associated to rather clinically mild AOM. The present study suggested that $M C$ had some pathogenic contribution to intractable AOM.

Conclusively, $H I$ was the most frequently isolated from the adenoid of OP children, and its prevalence was significantly higher in the OP children than in the OSA children. These findings may indicate that $H I$ is the most responsible pathogen for intractable AOM in the present days. Many of latest reports showed $H I$ prevalence had increased up to the highest frequency among otopathogenic bacteria over the world $[3,4,29]$. Furthermore, $H I$ was recently proved to have close relation to persistent and recurrent morbidity of AOM [3, 4, 30]. Results of the present study seem in agreement with those reports.

\section{CONCLUSION}

Transoral swab was attempted to know the real pathogenic bacteria in the adenoids of otitis-prone (OP) Japanese children. Non-typeable Haemophilus influenzae (HI) was the most frequently isolated from the OP children, and BLNAR was currently considered to have a significant role for intractability of acute otitis media.

\section{ACKNOWLEDGEMENT}

Authors greatly thank to Professors Masahiro Iida in Tokai University and Masamitsu Hyodo in Kochi Medical School for general support and their kindly providing us with a chance to publish this article.

\section{CONFLICT OF INTEREST}

None declared. 


\section{REFERENCES}

[1] Block SL. Causative pathogens, antibiotic resistance and therapeutic considerations in acute otitis media. Pediatr Infect Dis J 1997; 16: 449-56.

[2] Harabuchi Y, Kodama H, Faden H. Outcome of acute otitis media and its relation to clinical features and nasopharyngeal colonization at the time of diagnosis. Acta Otolaryngol 2001; 121: 908-14.

[3] Casey JR, Pichichero ME. Changes in frequency and pathogens causing acute otitis media in 1995-2003. Pediatr Infect Dis J 2004; 23: $824-8$.

[4] Barkai G, Leibovitz E, Givon-Lavi N, Dagan R. Potential contribution by nontypable Haemophilus influenzae in protracted and recurrent acute otitis media. Pediatr Infect Dis J 2009; 28: 46671 .

[5] Aebi C. Moraxella catarrhalis - pathogen or commensal? Adv Exp Med Biol 2011; 697: 107-16.

[6] Hotomi M, Billal DS, Shimada J, et al. High prevalence of Streptococcus pneumoniae with mutations in pbp1a, pbp2x, and pbp $2 b$ genes of penicillin-binding proteins in the nasopharynx in children in Japan. ORL J Otorhinolaryngol Relat Spec 2006; 68: 139-45.

[7] Foxwell AR, Kyd JM, Cripps AW. Nontypeable Haemophilus influenzae: pathogenesis and prevention. Microbiol Mol Biol Rev 1998; 62: 294-308.

[8] Brook I, Gober AE. Antimicrobial resistance in the nasopharyngeal flora of children with acute otitis media and otitis media recurring after amoxicillin therapy. J Med Microbiol 2005; 54: 83-5.

[9] van Kempen MJ, Vaneechoutte M, Claeys G, Verschraegen GL, Vermeiren J, Dhooge IJ. Antibiotic susceptibility of acute otitis media pathogens in otitis-prone Belgian children. Eur J Pediatr 2004; 163: 524-9.

[10] Papavasileiou K, Papavasileiou E, Voyatzi A, Makri A, Chatzipanagiotou S. Incidence and antimicrobial resistance of pathogenic bacteria isolated from children with acute otitis media in Athens, Greece, during the periods 2003-2004 and 2005-2007. Int J Antimicrob Agents 2009; 33: 183-4.

[11] Gates GA, Avery CA, Prihoda TJ, Cooper JC Jr. Effectiveness of adenoidectomy and tympanostomy tubes in the treatment of chronic otitis media with effusion. N Engl J Med 1987; 317: 144451.

[12] Maw R, Bawden R. Spontaneous resolution of severe chronic glue ear in children and the effect of adenoidectomy, tonsillectomy, and insertion of ventilation tubes (grommets). BMJ 1993; 306: 756-60.

[13] McClay JE. Resistant bacteria in the adenoids. Arch Otolaryngol Head Neck Surg 2000; 126: 625-9.

[14] Karlidağ T, Demirdağ K, Kaygusuz I, Ozden M, Yalçin S, Oztürk L. Resistant bacteria in the adenoid tissues of children with otitis media with effusion. Int J Pediatr Otorhinolaryngol 2002; 64: 3540.

[15] Göksu N, Ataoğlu H, Kemaloğlu YK, Ataoğlu O, Ozsökmen D, Akyildiz N. Experimental otitis media induced by coagulase negative staphylococcus and its L-forms. Int $\mathrm{J}$ Pediatr Otorhinolaryngol 1996; 37: 201-16.
[16] Hendolin PH, Markkanen A, Ylikoski J, Wahlfors JJ. Use of multiplex PCR for simultaneous detection of four bacterial species in middle ear effusions. J Clin Microbiol 1997; 35: 2854-8.

[17] Gok U, Bulut Y, Keles E, Yalcin S, Doymaz MZ. Bacteriological and PCR analysis of clinical material aspirated from otitis media with effusions. Int J Pediatr Otorhinolaryngol 2001; 60: 49-54.

[18] Hotomi M, Arai J, Billal DS, et al. Nontypeable Haemophilus influenzae isolated from intractable acute otitis media internalized into cultured human epithelial cells. Auris Nasus Larynx 2010; 37: 137-44.

[19] Forsgren J, Samuelson A, Ahlin A, Jonasson J, Rynnel-Dagöö B, Lindberg A. Haemophilus influenzae resides and multiplies intracellularly in human adenoid tissue as demonstrated by in situ hybridization and bacterial viability assay. Infect Immun 1994; 62: 673-9.

[20] Moriyama S, Hotomi M, Shimada J, Billal DS, Fujihara K, Yamanaka N. Formation of biofilm by Haemophilus influenzae isolated from pediatric intractable otitis media. Auris Nasus Larynx 2009; 36: 525-31.

[21] Kurono Y, Shigemi H, Kodama S, Mogi G. The role of adenoids in nasopharyngeal colonization with nontypeable Haemophilus influenzae. Acta Otolaryngol (Stockh) Suppl 1996; 523: 147-9.

[22] Brook I, Shah K, Jackson W. Microbiology of healthy and diseased adenoids. Laryngoscope 2000; 110: 994-9.

[23] Petrosillo N, Pantosti A, Bordi E, et al. Prevalence, determinants, and molecular epidemiology of Streptococcus pneumoniae isolates colonizing the nasopharynx of healthy children in Rome. Eur J Clin Microbiol Infect Dis 2002; 21: 181-8.

[24] Abut LI, Apan T, Otlu B, Calişkan A, Durmaz R. The characteristics of nasopharyngeal Streptococcus pneumoniae in children attending a daycare unit. New Microbiol 2008; 31: 357-62.

[25] Dagan R, Leibovitz E, Cheletz G, Leiberman A, Porat N Antibiotic treatment in acute Otitis Media promotes superinfection with resistant Streptococcus pneumoniae carried before initiation of treatment. J Infect Dis 2001; 183: 880-6.

[26] Piglansky L, Leibovitz E, Raiz S, et al. Bacteriologic and clinical efficacy of high dose amoxicillin for therapy of acute otitis media in children. Pediatr Infect Dis J 2003; 22: 405-13.

[27] de Vries SP, Bootsma HJ, Hays JP, Hermans PW. Molecular aspects of Moraxella catarrhalis pathogenesis. Microbiol Mol Biol Rev 2009; 73: 389-406.

[28] Broides A, Dagan R, Greenberg D, Givon-Lavi N, Leibovitz E. Acute otitis media caused by Moraxella catarrhalis: epidemiologic and clinical characteristics. Clin Infect Dis 2009; 49: 1641-7.

[29] Wiertsema SP, Kirkham LA, Corscadden KJ, et al. Predominance of nontypeable Haemophilus influenzae in children with otitis media following introduction of a $3+0$ pneumococcal conjugate vaccine schedule. Vaccine 2011; 29: 5163-70.

[30] Torretta S, Marchisio P, Drago L, et al. Nasopharyngeal biofilmproducing otopathogens in children with nonsevere recurrent acute otitis media. Otolaryngol Head Neck Surg 2012; [Epub ahead of print]. 